\title{
Water Analog Experimental Method for the Diffusion and Distribution of Alloy Elements in Liquid Steel during Ingot Filling Process
}

\author{
Jinwu KANG, Chao DONG, ${ }^{*}$ Xiaokun HAO, Gang NIE, Houfa SHEN and Baicheng LIU \\ Key Laboratory for Advanced Materials Processing Technology, Ministry of Education, School of Materials science and \\ Engineering, Tsinghua University, Beijing, 100084 China.
}

(Received on August 16, 2013; accepted on October 21, 2013)

\begin{abstract}
To physically simulate the alloy elements transportation and diffusion in the liquid steel during the making of heavy ingots, a water analogy experimental method is presented. In this method, methylene blue dye is used as solute to simulate the alloy element carbon in the melt steel. And a measurement method is proposed to measure the concentration of the solute, in which the laser reflection intensity detection method is used. The water analogy experiment setup is constructed. The multi-concentration pouring of a $438 \mathrm{t}$ ingot is investigated by this method. The concentration of the ladles decrease with the pouring consequence. The concentration variation curves with time at the tundish outlet and in the mold are acquired and analyzed. The tundish outlet concentration decreases gradually and no fluctuation occurs during the change of ladles. Negative concentration gradient is achieved at the end of pouring, which can be helpful for controlling of the macrosegration usually occurring in the heavy ingot.
\end{abstract}

KEY WORDS: water analogy; methylene blue dye; concentration; diffusion; liquid steel; ingot.

\section{Introduction}

For large ingots, macrosegregation is a common defect and a bottleneck in their quality control. ${ }^{1,2)}$ Generally speaking, macrosegregation is caused by the re-organization of chemical elements over long distance rather than around the dendrite arms. ${ }^{3)}$ The flow driven by temperature gradient, density difference of alloy elements and the mother alloy, and the deposition of advanced solidified grains into the bottom may lead to the macrosegregation of alloy elements.

As it is hard to directly observe the macrosegregation occurrence during the solidification of an ingot, numerical simulation has been a favorite research tool. Berkermann developed a model for multicomponent steel solidification with the consideration of the melt convection and fully coupled the conservation equations for the transport phenomena in the liquid, mush and solid. ${ }^{4}$ Li et al. developed a twophase macrosegregation model that incorporates heat transfer, melt convection, solute transport, equiaxed grain motion, and grain nucleation and growth. ${ }^{5}$ Nastec developed a generic framework studying macrosegregation in various casting processes using a computational fluid dynamics (CFD) code by solving the temperature, flow and solute balance in the multi-component alloy systems. ${ }^{6}$ ) Hervé Combeau presented a multiphase and multi-scale model that describes the evolution of the morphology of the equiaxed crystals. ${ }^{7)}$ Li et al. investigated the formation of

* Corresponding author: E-mail: dongchao_thu@163.com

DOI: http://dx.doi.org/10.2355/isijinternational.54.275 macrosegregation in a $360 \mathrm{t}$ multi-concentration poured steel ingot and found that the delay time for the last ladle has a significant effect on the macrosegregation. ${ }^{8)}$ On the other hand, water analogy experimental study is often applied in the investigation of the filling process of castings and the fluid flow in the tundish and mold for ingots and continuous casting. ${ }^{9,10)}$ Dye or particles are usually added as tracer to trace the fluid flow. And particles are added for the study of the removal of inclusions. In the area of segregation study, Zhang et al. adopted salt solution to simulate the concentration variation during the ingot pouring, he obtained the RTD curve by measuring the salt concentration at the tundish outlet. ${ }^{11)}$ Michalek et al. adopted aqueous solution of $\mathrm{KCl}$ for similar research. ${ }^{12)}$ Chen et al. compared the effect of KCL and $\mathrm{NaCl}$ solutions as tracer in fluid flow in the tundish and found $\mathrm{KCl}$ solution is more accurate. ${ }^{13)}$ Methylene blue or plastic particles are also used to illustrate the flow field of the tundish in some water analogy experiment. ${ }^{14)} \mathrm{Up}$ to date, the water analogy experiment is mainly applied for investigating the fluid flow. As for the research of multi-concentration pouring, it is of a potential method to investigate the concentration field in the tundish and ingot. But, there isn't yet research relating to solute selection and relative concentration measurement method.

This article presents a water analogy experimental method to physically simulate the alloy elements diffusion and transportation during filling process of ingots. Especially, the selection of solute and its measurement method is presented. And this method is applied into the research of the multi-concentration pouring process of a heavy ingot. 


\section{Theoretical Analysis of the Water Analogy Method}

\subsection{Similarity Analysis}

The theoretical basis for water analogy experiment is the similarity principle that if all of the similarity criterion are satisfied, the flow fields are similar to each other. In order to simulate the diffusion process of the alloy elements in liquid steel, both the velocity and concentration fields must be similar between water analogy experiment and the reality.

According to the hydraulics similarity theory, the Froude's and Reynolds numbers of the water analogy experiment should accord with those of the real filling process. Moreover, when both meet the self-molding condition, the influence of Reynolds number on the flow field can be ignored. ${ }^{15)}$ As a result, the Froude criteria is the similarity condition for the velocity field. ${ }^{16)}$ The Froude criteria is

$$
F_{r}=\frac{U^{2}}{g L}
$$

Where $U$ is the characteristic velocity, $L$ is the characteristic length, $g$ is gravitational acceleration.

If the size of the setup of the water analogy experiment is one $n$-th of the reality, i.e, the ratio of characteristic length between the water experiment and the reality is

$$
L_{\mathrm{w}}: L_{\mathrm{s}}=1: n
$$

Where the footnote ' $w$ ' denotes water analogy, 's' liquid steel.

Thus, according to Froude criteria, the ratio of the velocity should satisfy

$$
U_{\mathrm{w}}: U_{\mathrm{s}}=1: \sqrt{n}
$$

Where $U_{\mathrm{w}}$ is the characteristic velocity in the water analogy experiment and the $U_{\mathrm{s}}$ is the characteristic velocity in the reality.

The average velocity of the liquid steel at the outlet is

$$
U_{\mathrm{s}}=\frac{V_{\mathrm{s}}}{A_{\mathrm{s}} t_{\mathrm{s}}}
$$

Where $V_{\mathrm{s}}$ is the volume of the liquid steel, $A_{\mathrm{s}}$ is the section area of the outlet, $t_{\mathrm{s}}$ is the pouring time.

Among the similarity criteria, the mass transfer Peclet number $\left(P \mathrm{e}_{\mathrm{D}}\right)$ is defined as the ratio of the convective velocity to the diffusive velocity. ${ }^{17)}$ With Peclet number and Prandtl number, the heat and mass transfer similarity is obtained. ${ }^{18)}$ In other words, according to the similarity among flow, heat and mass transfer process, the flow field and mass transfer process will be similar at the same time by satisfying the Peclet criteria when the flow field is similar. The Peclet number is calculated by the following equation.

$$
P_{e D}=\frac{U L}{D}
$$

To meet the similarity of solute distribution, the Peclet criteria must be same. Thus, the ratio of diffusion coefficient is:

$$
D_{\mathrm{w}}: D_{\mathrm{s}}=\frac{U_{\mathrm{w}} L_{\mathrm{w}}}{U_{\mathrm{s}} L_{\mathrm{s}}}=1: n^{1.5}
$$

Where $D_{\mathrm{w}}$ is the diffusion coefficient of the simulate medium and $D_{\mathrm{s}}$ is the diffusion coefficient of the alloy ele- ment in steel.

If the ratios of characteristic length, velocity and diffusion satisfy Eqs. (2), (3) and (6), respectively, the flow field and solute distribution will be similarly between the water analogy experiment and reality, i.e., the concentration variation will be the same.

$$
\Delta c_{\mathrm{w}}: \Delta c_{\mathrm{s}}=1
$$

Where $\Delta c_{\mathrm{w}}$ and $\Delta c_{\mathrm{s}}$ is the relatively change of concentration, which doesn't change with the change of actual concentration of the solute.

\subsection{Selection of the Solute for Water Analogy Experi- ment}

According to the equation described above, the selection of the solute depends on the alloy element in the liquid steel. Their diffusion coefficient ratio should be in accordance with the similarity conditions. The diffusion coefficient for carbon in liquid steel under $1600^{\circ} \mathrm{C}$ is $0.2 \sim 6.0 \times 10^{-8} \mathrm{~m}^{2} / \mathrm{s},{ }^{19}$ ) while the diffusion coefficient for most solute in water under room temperature is about $10^{-9} \mathrm{~m}^{2} / \mathrm{s}$. Therefore, as $n$ is in the range of $2 \sim 10$, i.e., the size of water analogy experimental setup is reduced to $1 / 10 \sim 1 / 2$ of the actual one, the diffusivity is roughly in accordance with Eq. (6).

Salt has been used as solute in the water experiment. However, the measurement of salt concentration is not convenient because of measurement device may interfere with the flow for its relatively big size. Here, methylene blue dye, a popular used dye as tracer in water analogy experiment, is used as solute. Its diffusivity is $3.0 \times 10^{-9} \mathrm{~m}^{2} / \mathrm{s}^{20}$ )

\section{Measurement of the Concentration of Methylene Blue with Optical Fiber Sensor}

A new kind of concentration measurement method based on optical fiber sensor is developed to measure the concentration of colored solute in water. The measurement equipment is small enough to make the influence on flow field negligible and the range of measurement can be adjusted according to the experiment and the solute.

\subsection{Measurement Principle and Device}

Measurement of the concentration of methylene blue with optical fiber sensor is based on the principle that colored solute alters the transmittance of the solution. As the intensity of emission light is fixed, the intensity of light that returns varies with the concentration of the colored solute. By calibrating the concentration and the intensity of the return laser, the concentration of solute can be measured.

The optical fiber sensor measurement system consists of a probe, a pair of optical fibers including an emission fiber and a reception fiber, and a fiber amplifier which can produce monochromatic light and convert light signal to electric signal and record it. The probe is made of a $U$ shaped sheet metal with one side attached to the fibers, the other side a reflection surface. The distance of the end of the fiber to the reflection surface is $d$, than the distance that the light travels is $2 d$. The schematic diagram of the system is shown in Fig. 1.

The light from the emission fiber travels through the solution and is reflected by the metal surface to the fiber ampli- 
fier through the reception fiber. The fiber amplifier converts the light signal to an electric signal and records it. As the reflection metal surface is about $10 \mathrm{~mm}$ from the emission end, the probe is relatively small, its influence on the flow field can be neglected. The $U$ shaped metal is made of high strength sheet metal to avoid distortion caused by pulse of flow.

The response time of this optical fiber sensor measurement system is less than $0.1 \mathrm{~s}$. Its measurement error is limited to $5 \%$. And it is stable and is not influenced by the environment light.

\subsection{Measurement of the Concentration of Methylene Blue Solution}

The intensity decay of light is mainly influenced by the distance passing through the solution and the darkness of the solution.

Lambert-Beer's law points out that when a light of intensity $I_{0}$ travels through solution with concentration $c$ and distance $d$, Assuming there isn't scattering, the relation between $I_{0}$ and the reception light intensity $I$ is shown as below.

$$
\lg \left(\frac{I_{0}}{I}\right)=\lg \left(\frac{1}{T}\right)=\varepsilon \cdot(2 d) \cdot c
$$

Where $T$ is called the transmittance of solution and $\varepsilon$ is a molar absorption coefficient. For a certain kind of solution, its molar absorption coefficient for a monochromatic light is a constant.

The light signal is transferred to a digital signal by the fiber amplifier by the following equation,

$$
\Gamma=k \lg I
$$

Where, $\Gamma$ is the apparent light intensity shown on the screen, $k$ is a constant.

So, the concentration of solute can be expressed as the function of the fiber amplifier output $\Gamma$ as the equation below.

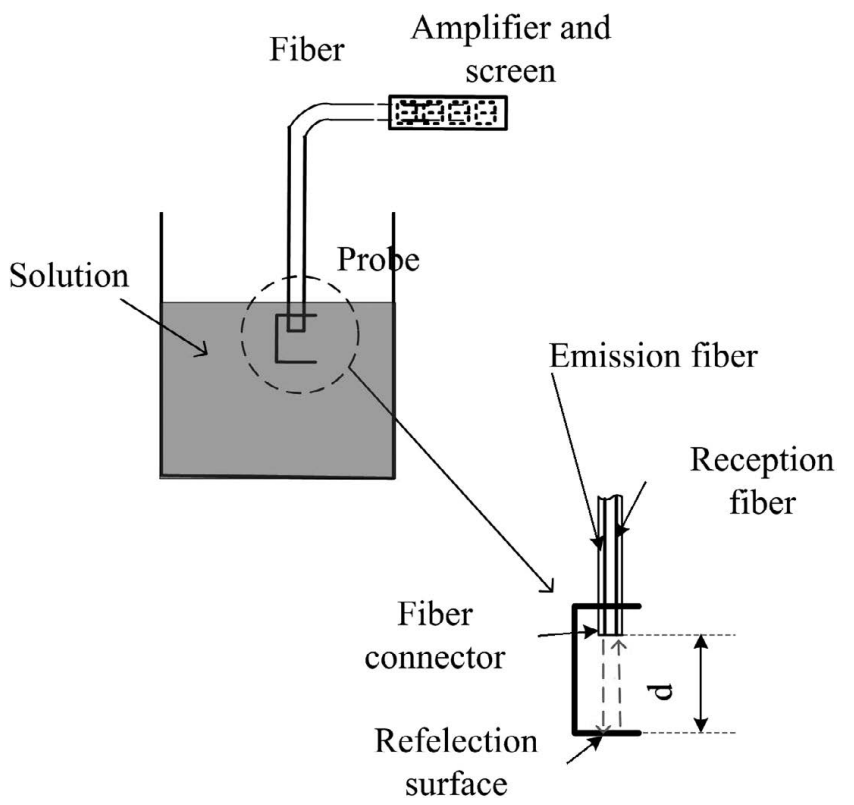

Fig. 1. Optical fiber sensor measurement system for colored solution.

$$
c=B-A \Gamma
$$

Where $A$ and $B$ are constants determined by the system and $\Gamma$ is the amplifier output. The constant $A$ is determined by $\varepsilon$ and $d$. So, the range of measurement can be satisfied by adjusting the reflection distance.

For a given fiber measurement system, the wavelength of the laser is $640 \mathrm{~nm}$, and the concentration range of methylene blue varies from $0.001 \%-0.041 \%$. The reflection distance $d$ is $10 \mathrm{~mm}$ and reflection surface is $4 \mathrm{~mm} \times 2 \mathrm{~mm}$ large. The diameter of the optical fiber cable is $2 \mathrm{~mm}$.

The methylene blue solution is obtained by dissolving weighted pure methylene blue powder into distilled water. The relation between the concentration $c$ and the amplifier output $\Gamma$ for the given measurement system is shown as Fig. 2.

From Fig. 2 the linear fitting equation between $c$ and $\Gamma$ for this measurement sensor is obtained

$$
c=0.41-5.14 \times 10^{-3} \Gamma
$$

By this equation, several methylene blue solutions are tested and their results are shown in Fig. 3. The error is within $\pm 5 \%$.

The parameters of the system are listed in Table 1. The probe is so small compared to the analogy model that its influence on the flow field can be neglected. The measurement system should be calibrated at the first time and regularly after a period of time because of shaking of fiber, bubbles attaching on the reflection metal surface and the contaminated fiber connector may lead to errors. To better

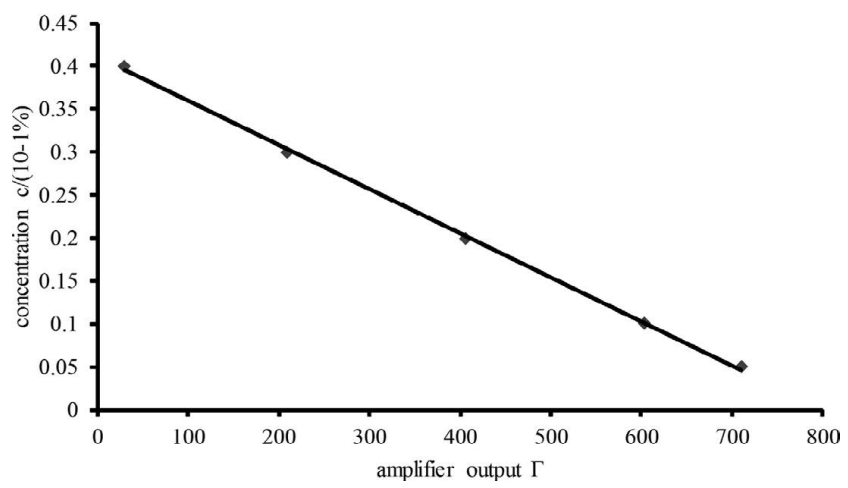

Fig. 2. The relationship between the output $\Gamma$ and the concentration $\mathrm{c}$ of methylene blue solution as re-flection distance is $10 \mathrm{~mm}$.

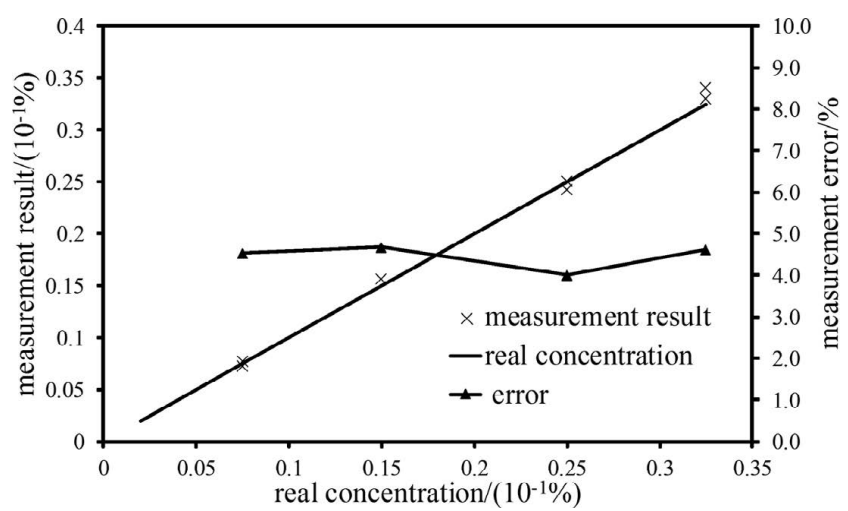

Fig. 3. Errors of the measurement of fiber sensor system. 
measure the concentration of methylene blue, the range of $0.012 \%-0.045 \%$ is suggested.

\section{Filling Process Experiment of a $438 \mathrm{t}$ Ingot}

The water analogy experiment of the multi-concentration pouring process of a $438 \mathrm{t}$ ingot is carried out. The material of the ingot is $30 \mathrm{Cr}_{2} \mathrm{Ni}_{4} \mathrm{MoV}$, and its carbon content is $0.26 \%$.

\subsection{Experiment Process and Parameters}

The multi-concentration pouring process in tundish is divided into three stages. Stage I is called tundish filling stage during which the outlet of tundish is clogged by a stopper rod and the liquid steel is poured into tundish from the first ladle till the liquid level in the tundish rises to $2 / 3$ height. Stage II is called the stable stage, the tundish outlet is released for pouring, and keep the liquid level unchanged by adjusting the flow rate. When the residual liquid steel in ladle 1 is all poured into the tundish, the liquid steel in ladle 2 starts to fill the tundish. And then pour all the other ladles by sequence. Stage III is called tundish empty stage. In this stage, there is no more filling of the tundish, the liquid level in the tundish begins to descend till the pouring process ends. The carbon concentration may be different for all the ladles to form nonuniform distribution of carbon, usually from high concentration to low concentration and finally negative segregation in the mold so as to reduce the macrosegregation formed during the solidification process. This multi-concentration pouring process is shown in Fig. 4.

To satisfy the Eq. (6), the similarity ratio between water analogy model and the real situation is 8 . All the production and experiment parameters are listed in Table 2. For the ingot, four ladles with different concentration are deter-

Table 1. Conditions of the sensor and features of the measurement system.

\begin{tabular}{lc|lc}
\hline \multicolumn{2}{c|}{ Conditions of the sensor } & \multicolumn{2}{c}{ Measurement features } \\
\hline Reflection distance $(\mathrm{mm})$ & 10 & Error (\%) & $<5$ \\
Probe size $(\mathrm{mm})$ & $10 \times 4 \times 2$ & Response time (s) & $<0.1$ \\
Fiber cable diameter $(\mathrm{mm})$ & 2 & Measurement range $\left(10^{-1} \%\right)$ & $0-0.410$ \\
Wave length of light $(\mathrm{nm})$ & 640 & Measurement sensitivity $\left(10^{-1} \%\right)$ & 0.001 \\
\hline
\end{tabular}

mined, which are $90 \mathrm{t}$ with $0.33 \% \mathrm{C}, 90 \mathrm{t}$ with $0.30 \% \mathrm{C}, 105$ $\mathrm{t}$ with $0.26 \% \mathrm{C}$ and $155 \mathrm{t}$ with $0.33 \% \mathrm{C}$ in pouring sequence, so the ladles in the water analogy experiment are $22.5 \mathrm{~kg}$ with $0.04 \%, 22.5 \mathrm{~kg}$ with $0.036 \%, 26 \mathrm{~kg}$ with $0.032 \%$ and $40 \mathrm{~kg}$ with $0.24 \%$ methylene blue, respectively. The size of tundish model is $\Phi 400 \mathrm{~mm} \times 400 \mathrm{~mm}$, one eighth of $\Phi 3200$ $\mathrm{mm} \times 3200 \mathrm{~mm}$ of the real tundish. While the flow rates in experiment and production are $3.2 \mathrm{~L} / \mathrm{min}$ and $573 \mathrm{~L} / \mathrm{min}$ (characteristic velocity $0.47 \mathrm{~mm} / \mathrm{s}$ and $1.22 \mathrm{~mm} / \mathrm{s}$ ), respectively. The tundish outlet size is also reduced to one eight. During the experiment, the flow rate is controlled, so the pouring time is also fitful for the similarity ratio.

An experiment model of this process is set up. One probe is set at the tundish outlet to measure the outlet concentration of the tundish and three probes are placed in the center of the mold along a fixed bracket to measure the center concentration variation at different heights, $150 \mathrm{~mm}, 300 \mathrm{~mm}$, and $450 \mathrm{~mm}$. The fixed bracket is as thin as $5 \mathrm{~mm}$ in diameter. The experiment system is shown in Fig. 5.

\subsection{Result and Analysis}

Because of the similarity between the water analogy experiment and the real steel liquid, the relative solute concentration is the same, and then the concentration variation of the methylene blue with time can be converted to the variation of carbon concentration in liquid steel with time.

Figure 6 shows experimental concentration variation at the tundish outlet and the converted carbon concentration during the pouring process of the $438 \mathrm{t}$ ingot and the change of the liquid level in the tundish. The result of water analogy

Table 2. real situation and experiment parameter.

\begin{tabular}{lccc}
\hline & Real situation & Water analogy & Ratio \\
\hline Tundish size & $\Phi 3200 \times 3200(\mathrm{~mm})$ & $\Phi 400 \times 400(\mathrm{~mm})$ & 8 \\
Outlet size & $\Phi 100(\mathrm{~mm})$ & $\Phi 12(\mathrm{~mm})$ & 8 \\
Ingot size & $\begin{array}{l}4140 \mathrm{~mm} \times 4140 \mathrm{~mm} \\
\times 7931 \mathrm{~mm}\end{array}$ & $\begin{array}{c}500 \mathrm{~mm} \times 500 \mathrm{~mm} \\
\times 1000 \mathrm{~mm}\end{array}$ & 8 \\
Ladle concentration & $(0.33,0.30,0.26,0.20)$ & $(0.40,0.36,0.32,0.24)$ & 8.25 \\
Ladle pouring quantity & $(90,90,105,155)(\mathrm{t})$ & $(22.5,22.5,26,40)(\mathrm{Kg})$ & $7.8 \times 8^{3}$ \\
Ladle pouring time & $(20,20,24,34)(\mathrm{min})$ & $(7,7,8.5,12)(\mathrm{min})$ & $8^{0.5}$ \\
Ladle pouring flow & $573(\mathrm{~L} / \mathrm{min})$ & $3.2(\mathrm{~L} / \mathrm{min})$ & $8^{2.5}$ \\
\hline
\end{tabular}

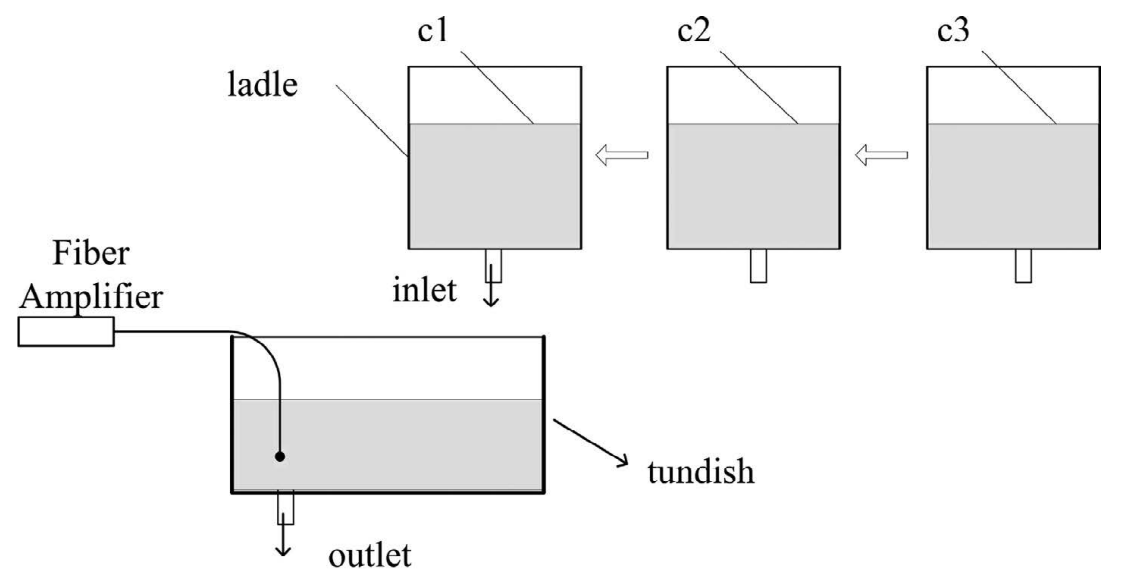

Fig. 4. Multi-concentration pouring process of large ingots. 
experiment is shown on the top and right axes, while the carbon concentration is shown on the bottom and left axes. It can be seen from Fig. 6 that the concentration at the tundish outlet doesn't change until the liquid of ladle 2 gets into the tundish. During the pouring of ladle 2 to the final one, the concentration descends continuously. And almost no fluctuation occurs during the change of ladles. The outlet concentration of tundish is always higher than that of the ladle being poured. At the beginning of the empty process of the tundish, the outlet concentration is still higher than that of the last ladle. The final concentration is close to that of the last ladle. Form the results it can be deduced that there is a mixing process of the current flow and the existed liquid in the tundish during pouring. So, the concentration at the tundish outlet changes gradually. Because the concentration of the former ladle is higher than that of the current ladle, the tundish outlet concentration is always higher than that of the current ladle, especially for ladle 2 . On the other hand, it is also affected by the volume of each ladle. The bigger a

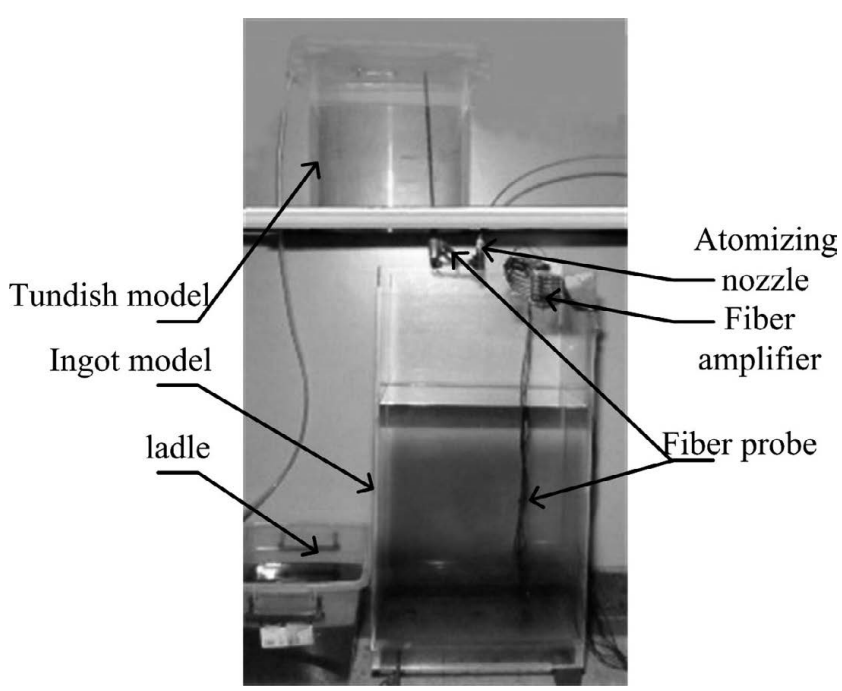

Fig. 5. Water analogy experiment apparatus of multi-concentration pouring process of a $438 \mathrm{t}$ ingot. ladle is, the smaller concentration difference at the end of this ladle pouring. For example, at the end of ladle 3, the concentration difference between the tundish outlet and that of ladle 3 is $0.17 \%$, while the difference at the end of ladle 4 is $0.01 \%$. Because ladle 4 is far bigger than ladle 3 . If the last ladle is of small volume, the final tundish outlet concentration should be far higher than that of the last ladle.

The measurement results of three points with heights of $150 \mathrm{~mm}, 300 \mathrm{~mm}, 450 \mathrm{~mm}$ in the ingot are shown in Fig. 7. The probe at $150 \mathrm{~mm}$ is submerged at $17.5 \mathrm{~min}$ during the experiment, while the probes at $300 \mathrm{~mm}$ and $450 \mathrm{~mm}$ are submerged at $29 \mathrm{~min}$ and $39 \mathrm{~min}$ respectively. Only after the probe is submerged, its concentration detection result is recorded and plotted in Fig. 7. From Fig. 7 it can be seen that, like the outlet concentration of the tundish, the concentration of the measurement points also decrease gradually during the pouring process. When the probe is submerged, its concentration is above the tundish outlet concentration at same time. That means mixing occurs in the mold, which will decrease the concentration gradient. Therefore, the bottom concentration should be higher than that of the first ladle, and the top concentration higher than the last ladle. The effective concentration difference between the first and last ladle will be narrowed. And for points at different heights, there shows a concentration gradient with concentration decreases with height. At the end of the pouring process, the concentration in the heights of $150 \mathrm{~mm}, 300 \mathrm{~mm}$, and $450 \mathrm{~mm}$ is $0.26 \%, 0.21 \%, 0.20 \%$, respectively.

Based on the result and analysis, it can be found that the multi-concentration-pouring process leads to a certain kind of concentration distribution in the ingot from bottom to up, the bottom concentration is close to the first ladle, the top is close to the last ladle. If the concentration of ladles decreases with the pouring sequence, a negative concentration gradient appears in the ingot after pouring, which can be helpful for controlling the macrosegregation in ingot that usually features as a positive concentration gradient. However, after the convection and diffusion in the mold, the concentration gradient is reduced than that of the ladles.

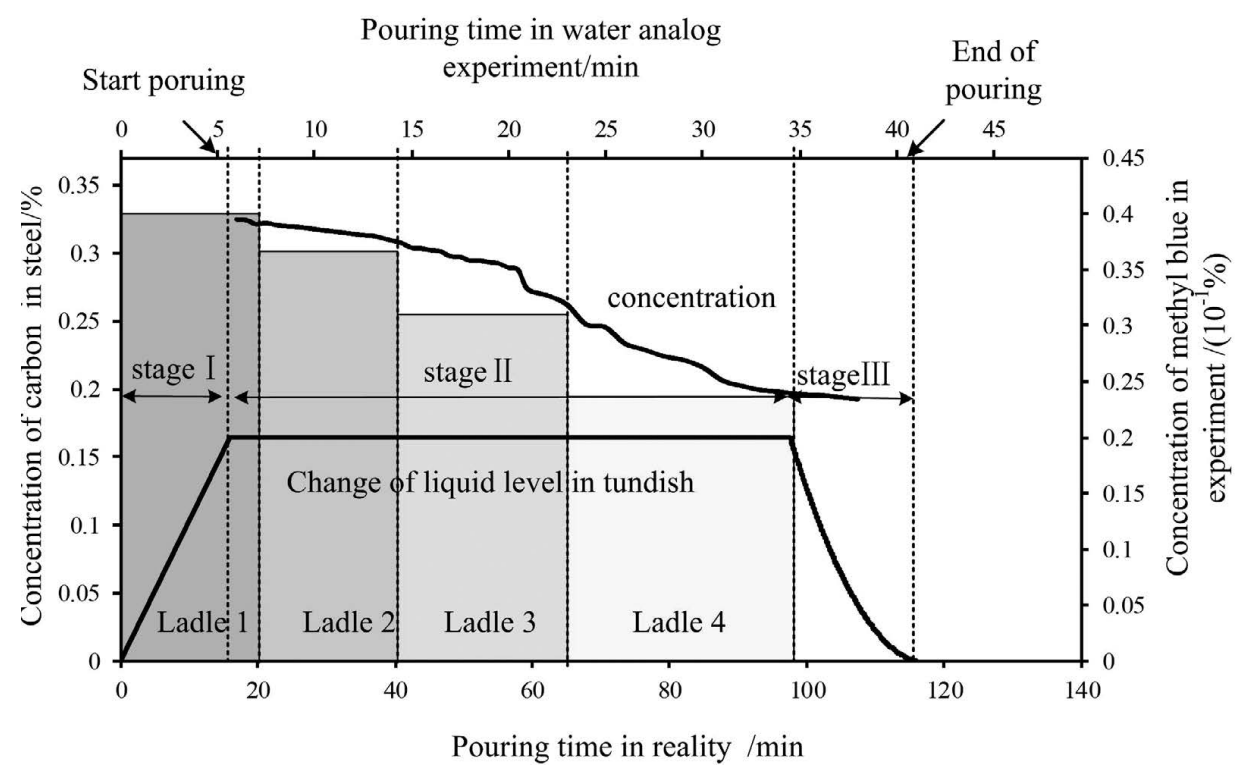

Fig. 6. Concentration at the tundish outlet of the $438 \mathrm{t}$ ingot in four-ladle pouring. We enlarged Figs. 6 and 7 . 
Pouring time in water analog experiment/min

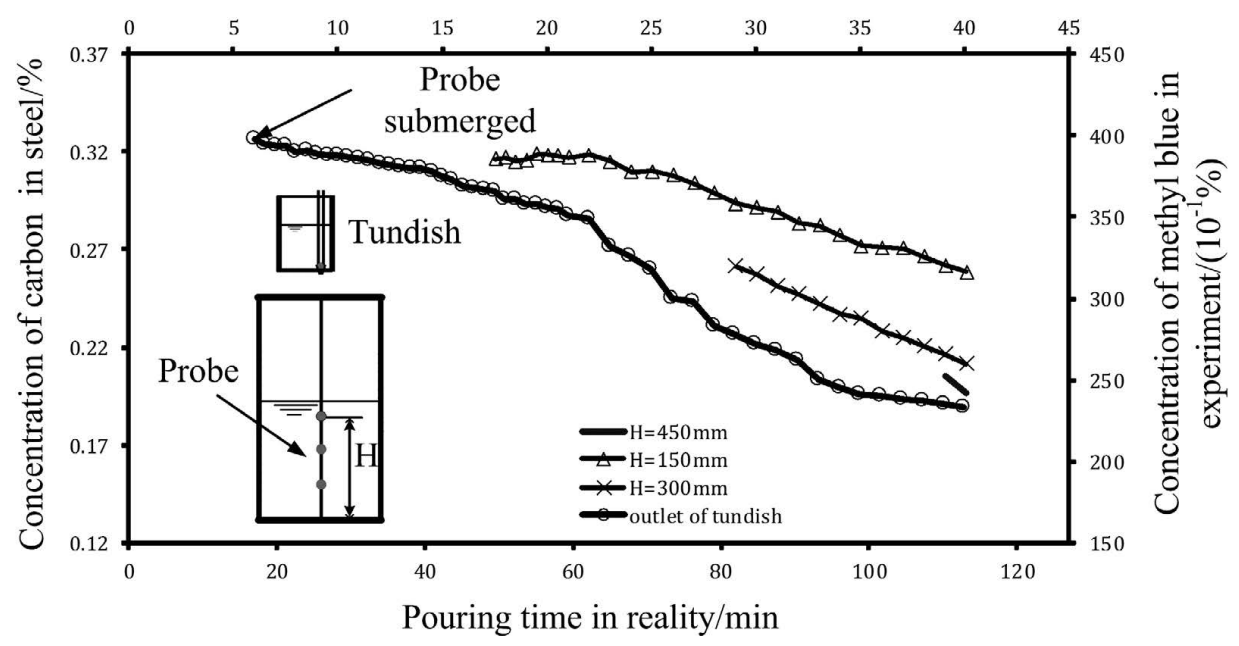

Fig. 7. Concentration in the ingot during pouring process.

\section{Conclusion}

(1) A water analogy experimental method is proposed to study the mass transfer in tundish and ingot. According to the similarity analysis, Methylene blue dye can be used to simulate the alloy elements' transportation behavior in liquid steel.

(2) An optical fiber sensor measurement system is developed to measure the concentration of the Methylene blue solution with good accuracy, fast response and neglectable influence on the flow.

(3) The multi-concentration-pouring process of a $438 \mathrm{t}$ ingot is investigated with the developed system. The concentration of the ladles decrease with the pouring consequence. The tundish outlet concentration changes continuously and gradually during pouring process, and almost no fluctuation occurs during change of ladles. As the mixing caused by convection and diffusion in tundish and mold happens, the effective concentration difference between the first and last ladle will be narrowed. The solute distribution in the mold shows a negative concentration gradient in the ingot from bottom to up, which can be helpful for controlling the macrosegregation in the ingot.

\section{Acknowledgement}

The project is funded by National Science and Technology Major Project of the Ministry of Science and Technology of China under Project No. 2012ZX04012011 and National
Basic Research Program of China (No. 2011CB012900).

\section{REFERENCES}

1) K. Sakamoto, T. Kusamichi, S. Nanba, T. Nakagawa, K. Nakayama and T. Takebayashi: Kobe Res. Dev. (Japan), 47 (1997), 62.

2) D. R. Liu: Int. J. Cast Met. Res., 26 (2013), 143.

3) D. R. Liu, X. H. Kang, P. X. Fu and D. Z. Li: Kovove Mater., 49 (2011), 1.

4) J. P. Gu and C. Beckermann: Metall. Mater. Trans. A, 30 (1999), 1357.

5) W. S. Li and H. F. Shen: IOP Conf. Series: Mater. Sci. Eng., 33 (2012), 012090.

6) L. Nastac: ISIJ Int., 50 (2010), 1829.

7) H. Combeau, M. Zaloznik, S. Hans and P. E. Richy: Metall. Mater. Trans. B, 40 (2009), 289.

8) J. Li, D. R. Liu, X. H. Kang and D. Z. Li: IOP Conf. Series: Mater. Sci. Eng., 33 (2012), 012092.

9) A. J. Davis and S. J. Asquith: 13th SDCE International Die Casting Exposition \& Congress, Society of Die Casting Engineers, Illinois, (1985).

10) X. Xue and Y. B. Zhang: Mater. Sci. Technol., 10 (2002), 77.

11) S. H. Zhang: Studies on Multi-Phase Flow Transport Phenomena in Several Chemical and Metallurgical Reactors, Central South University, Changsha, (2004).

12) K. Michalek, K. Gryc, M. Tkadleckova and D. K. Bocek: Arch. Metall. Mater., 57 (2012), 291.

13) C. H. Chen, G. G. Cheng, H. B. Sun, Z. B. Hou, X. CH. Wang and J. Q. Zhang: Steel Res. Int., 83 (2012), 1141.

14) J. Li: Study on the Fluid Flow in a Multi-heat Teeming Tundish for Heavy Steel Ingot, Chongqing University, Chongqing, (2011).

15) B. Liu: Heavy Casting Forging, 2 (2006), 11.

16) B. J. Wang, Y. B. Zhong and Y. Wang: J. Univ. Sci. Technol. Beijing, 31 (2009), 625.

17) S. Bhattacharya and S. T. Hwang: J. Membrane Sci., 132 (1997), 73.

18) F. Larachi, C. Alix, B. P. A. Grandjean and A. Bernis: Trans. Icheme, 81 (2003), 689.

19) D. Goldberg and G. R. Belton: Metall. Trans., 5 (1974), 1643.

20) S. Mochzuki: Proc. PSFVIP-4, Chamonix, (2003), 1. 